\section{Further Aspects of Humus Decomposition}

RECENT experiments have shown that the characteristic flush of decomposition that follows the wetting of a dry soil can be partly prevented by the addition of $0.5 \mathrm{gm}$. of activated chareoal (per $30 \mathrm{gm}$. soil) and almost completely prevented by $1.5 \mathrm{gm}$. or more (Fig. 1). When the soils were then ovendried and re-wetted without further treatment a similar result was obtained. When a slowly decomposing moist soil was treated with ether vapour under vacuum and the excess vapour then removed, a similar flush of decomposition resulted which was also repeated with successive treatments. Here, however, the flush of decomposition was not in. hibited by charcoal.

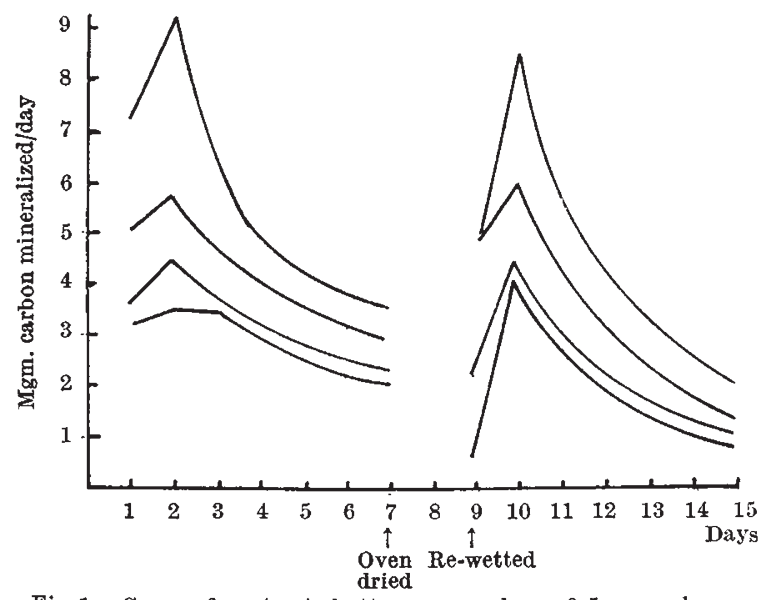
Fig. 1. Curves, from top to bottom: no carbon; $0.5 \mathrm{gm}$. carbon;
$1.0 \mathrm{gm}$. carbon; $1.5 \mathrm{gm}$. carbon

These results afford an insight into the factors involved in humus decomposition and the partial sterilization of soils. Soil drying increases the amount of organic material later going into solution and when this is adsorbed by the charcoal the flush of decomposition is inhibited. Ether vapour has, however, been found here to have no effect on the amount of organic material that will dissolve. Nevertheless, the flush of decomposition still occurs and this may be ascribed to the high microbial activity associated with the youthful phase of the newly developing population and the presence of dead microbial cells which can serve as readily available substrate ${ }^{1}$.

Since heat causes diffusion of amino-acids from within the cells ${ }^{2}$, it is possible that the compounds adsorbed by the charcoal are amino-acids or similar microbially derived compounds and that these, serving as available substrate, are responsible for the flush of decomposition following the wetting of an oven-dry soil. Ether, on the other hand, reduces cell permeability ${ }^{3}$ and was found here to be ineffective in increasing the amount of organic material going into solution. Charcoal, therefore, has no effect after ether treatment in inhibiting the flush of decomposition which must depend on the utilization of relatively intact dead cells as substrate. Clearly, the marked decomposition that follows partial sterilization is not necessarily dependent on increased solubility of substrate. The main factor involved appears to be microbial death, whether accompanied by lysis of the cell contents or not, the remains then serving as available substrate when normal conditions are restored. The newly developing population will also be more active at first than later on.
The results of the charcoal experiment conform with what has been said. It will be noted that the magnitude of the second flush of decomposition is related to the magnitude of the first. The larger this is the bigger the microbial population will be and the greater the amount of substrate available, after killing, for the succeeding population. Such a sequence of decompositions can, however, only be maintained if substrate additional to that supplied by the microorganisms is available, since much of the microbially derived substrate is lost as carbon dioxide during its utilization by the newly developing population. It has been reported ${ }^{4}$ that when decomposable material is added to a soil a highly active microbial population develops with consequently enhanced humus decomposition while the supply of energy material lasts. Microbially derived substrate could serve a similar function, the succeeding population building up to an equilibrium-level depending not only on the amount of microbially derived substrate available but also on the kind and amount of humus present. This would explain why the sequence of decompositions are of approximately equal magnitude and are also dependent on the carbon content of the soil.

East African Agriculture and

H. F. BIRCH

Forestry Research Organization, P.O. Box 21,

Kikuyu, Kenya. Sept. 1.

${ }^{1}$ Steinhaus, E. A., and Birkeland, J. M., J. Bact., 38, 249 (1939).

${ }^{2}$ Vas, K., Agrokémia es Talajtan, 2, 1 (1953). Chem. Abstracts, 48, 794d (1954).

${ }^{3}$ Knaysi, G., "Elements of Bacterial Cytology" (Constable, London, $1951)$.

4 Broadbent, F. E., and Norman, A. G., Soil Sci. Soc. Amer. Proc., 11, 264 (1946).

\section{Chlorine Deficiency in Soils}

Is the past five years chlorine has been shown to be an essential micronutrient for a number of vege. table and crop plants ${ }^{1,2}$. More recently, the need for chlorine was demonstrated in the annual pasture plant, subterranean clover (Trifolium subterraneum, L. $)^{3}$. The solution culture medium used in these experiments was prepared by adding highly purified inorganic salts to twice-distilled water. In addition, the plants were grown in glasshouses fitted with filters to purify the incoming air.

The economic importance of chlorine as a plant nutrient will depend on whether or not plant growth in the field is limited by chlorine deficiency. Although a great deal of information has been accumulated regarding saline soils, there is little known of the occurrence of soils very low in chlorine. As a first step in investigating this problem, I collected soil samples from various locations in California. These were selected with regard to distance from the sea, high altitude, heavy rainfall or with permeable, welldrained soil profiles. It was thought that these conditions were likely to produce soils low in chlorine. On analysis of saturation extracts by electrometric titration, the two soils lowest in chlorine were found to contain only three to five micro-equivalents per $100 \mathrm{gm}$. These soils, a Holland sandy loam and a Cometa coarse, sandy loam, were found in the foothills of the Sierra-Nevada Range at points about 65 miles apart, and 100 miles from the ocean. Both sites were carrying a poor growth of annual pasture plants.

Subterranean clover (var. Mt. Barker) was planted in $2 \cdot 4-\mathrm{kgm}$. pots containing these soils, and then 